\title{
APPROXIMATE FUNCTIONAL INEQUALITIES BY ADDITIVE MAPPINGS
}

\section{HARK-MAHN KIM, JURi LEE AND EUNYOUNG SON}

Abstract. Let $n$ be a given positive integer, $G$ an $n$-divisible abelian group, $X$ a normed space and $f: G \rightarrow X$. We prove a generalized Hyers-Ulam stabitity of the following functional inequality

$$
\|f(x)+f(y)+n f(z)\| \leqslant\left\|n f\left(\frac{x+y}{n}+z\right)\right\|+\varphi(x, y, z), \quad \forall x, y, z \in G,
$$

which has been introduced in [3], under some conditions on $\varphi: G \times G \times G \rightarrow[0, \infty)$.

Mathematics subject classification (2010): 39B72, 39B82.

Keywords and phrases: Cauchy Jensen inequality, generalized Hyers-Ulam stability.

\section{REFERENCES}

[1] Z. GAJDA, On the stability of additive mappings, Intern. J. Math. Math. Sci. 14 (1991), 431-434.

[2] P. GǍvRUTA, A generalization of the Hyers-Ulam-Rassias stability of approximately additive mappings, J. Math. Anal. Appl. 184 (1994), 431-436.

[3] Z.-X. GAO, H.-X. CAO, W.-T. Zheng AND LU XU, Generalized Hyers-Ulam-Rassias stability of functional inequalities and functional equations, J. Math. Inequal. 3(1)(2009), 63-77.

[4] D. H. Hyers, On the stability of the linear functional equation, Proc. Nat. Acad. Sci. U.S.A. 27 (1941), $222-224$.

[5] TH. M. Rassias, On the stability of the linear mapping in Banach spaces, Proc. Amer. Math. Soc. 72 (1978), 297-300.

[6] TH. M. RASSIAS, The stability of mappings and related topics, In 'Report on the 27th ISFE', Aequ. Math. 39 (1990), 292-293.

[7] TH. M. RASSIAS AND P. ŠEMRL, On the behaviour of mappings which do not satisfy Hyers-UlamRassias stability, Proc. Amer. Math. Soc. 114 (1992), 989-993.

[8] S. Jung, On Hyers-Ulam-Rassias stability of approximately additive mappings, J. Math. Anal. Appl. 204 (1996), 221-226.

[9] S. M. Ulam, A Collection of the Mathematical Problems, Interscience Publ. New York, 1960. 